\title{
Enhancing Mechanical Properties of the Spark Plasma Sintered Inconel 718 Alloy by Controlling the Nano-Scale Precipitations
}

\author{
Shuaijiang Yan ${ }^{1}$, Yun Wang ${ }^{1}$, Qingxiang Wang ${ }^{1,2}$, Chengsong Zhang ${ }^{1}$, Dazhi Chen ${ }^{1}$ and \\ Guodong Cui ${ }^{1,3, *(\mathbb{D})}$ \\ 1 School of Materials Science and Engineering, Southwest Jiaotong University, Chengdu 610031, China; \\ ysj@my.swjtu.edu.cn (S.Y.); wy_swjtu@163.com (Y.W.); wangqx1981@163.com (Q.W.); \\ cszhang@home.swjtu.edu.cn (C.Z.); cdz@swjtu.edu.cn (D.C.) \\ 2 Sino-Euro Materials Technologies of Xi'an Co., Ltd., Xi'an 710018, China \\ 3 Key Laboratory of Advanced Technologies of Materials, Ministry of Education, Chengdu 610031, China \\ * Correspondence: gdcui@swjtu.edu.cn; Tel.: +86-136-8848-1468
}

Received: 11 September 2019; Accepted: 11 October 2019; Published: 13 October 2019

\begin{abstract}
The present study aimed to optimize the phase constituents and mechanical properties of the spark plasma sintered (SPS) Inconel 718 (IN718) alloy. A series of heat treatment routes were designed based on the phase relations in IN718 and performed for the optimization. The microstructure and phase compositions of the SPS IN718 alloys were examined by using X-ray diffraction (XRD), scanning electron microscopy (SEM), energy disperse spectroscopy (EDS), and transmission electron microscopy (TEM). The mechanical properties of the samples were characterized at room temperature and at $650{ }^{\circ} \mathrm{C}$. The results showed that large amounts of $\gamma^{\prime \prime}\left(\mathrm{Ni}_{3} \mathrm{Nb}\right)$ and $\gamma^{\prime}\left(\mathrm{Ni}_{3}(\mathrm{Al}, \mathrm{Ti})\right)$ strengthening phases precipitated in the IN718 alloy after direct aging (DA) of the as-fabricated sample. Moreover, the mechanical properties of the DA sample were comparable to that of the best one of the solution-treated and aged counterparts. The analysis showed that the rapid sintering and solid solution treatment of the IN718 alloy were achieved simultaneously by SPS. In the case of the SPS IN718 material, the direct aging regime had the same heat treatment effect as the conventional solid solution and aging treatment. This contributes toward improving the production efficiency and reduces manufacturing costs in the actual production process.
\end{abstract}

Keywords: Inconel 718 superalloy; spark plasma sintering; nano-scale precipitation; microstructure; mechanical property

\section{Introduction}

As a precipitation strengthening alloy, the Inconel 718 (IN718) alloy has been widely used in the aircraft industry due to its good corrosion resistance and excellent mechanical properties at elevated temperatures [1-3]. IN718 is strengthened mainly by the nano-scale $\gamma^{\prime \prime}\left(\mathrm{Ni}_{3} \mathrm{Nb}\right)$ and $\gamma^{\prime}\left(\mathrm{Ni}_{3}(\mathrm{Al}, \mathrm{Ti})\right)$ phases. The $\gamma^{\prime \prime}$ phase has a disc shape with a body centered tetragonal (bct) structure [4,5]. The $\gamma^{\prime}$ phase has a cubic (fcc) structure and precipitates as a cube-to-cube relationship with the matrix [6]. Due to the composition of the alloy, there will be more $\gamma^{\prime \prime}$ than $\gamma^{\prime}$ in the alloy. The $\gamma^{\prime \prime}$ phase is metastable and can transform into the $\delta\left(\mathrm{Ni}_{3} \mathrm{Nb}\right)$ phase at high temperatures [7-9]. Appropriate amounts of $\delta$ phases at grain boundaries can refine the grain sizes and improve the resistance to grain boundary creep fracture [10-12]. However, large amounts of $\delta$ phases will decrease the mechanical strength, since it consumes $\mathrm{Nb}$ atoms, leading to the loss of $\gamma^{\prime \prime}$ phases in this alloy [13]. The relatively high $\mathrm{Nb}$ concentration also results in the precipitation of carbide $(\mathrm{NbC})$ and Laves $\left((\mathrm{Ni}, \mathrm{Fe}, \mathrm{Cr})_{2}(\mathrm{Nb}, \mathrm{Mo}, \mathrm{Ti})\right)$ phases in IN718. 
With the development of high strength, precision, and fabrication efficiency of IN718 components, the conventional casting and forging methods are difficult to meet the increasingly strict requirements [14]. Spark plasma sintering (SPS), as a relatively new powder metallurgy (P/M) technique, is well-suited for the preparation of IN718 alloy due to its assurance of high fabrication efficiency, relative density, and compressive strength of the SPS IN718 material [15]. Compared with other P/M techniques, SPS is assisted by a highly-pulsed DC, which provides the heat directly inside the sample by the Joule effect [16]. With the simultaneous application of uniaxial pressure, the samples can be fabricated rapidly by SPS [17]. Due to these unique characteristics of the SPS technique, the microstructure of the SPS material is markedly different from that of the same material fabricated by other P/M methods [15,18-20]. The special microstructures of SPS materials will require different post-process heat treatment in order to obtain the desired properties. Niu et al. [21] reported that the solution annealing temperature required for the SPS Ti-22Al-25Nb alloy is lower than the SLMed product. The work of Chua et al. [22] and Mahathaninwong et al. [23] indicated that the similar heat treatment route had various effects on the mechanical properties of SPS and rheocasting 7075 alloys. Mondet et al. [24] found that for the SPS-fabricated AZ91 alloy, the in-situ precipitation treatment is more preferred than the traditional T6 heat treatment because it led to a more significant improvement of the mechanical properties. Therefore, the heat treatment regime of the SPS-fabricated alloys needs to be optimized because of their special microstructures. As for the SPS-fabricated IN718, existing studies adopted the heat treatment schedule for the cast and wrought materials $[15,25]$. The traditional solution treatment and aging scheme shows the strengthening effects on SPS IN718. However, the optimized heat treatment route specifically for SPS IN718 alloy remains unclear, and methods for tuning the mechanical properties through heat treatment are short of guidance. Therefore, it is of upmost importance to design the specific heat treatment route for the SPS IN718 alloy with the aim of tailoring the microstructure and tuning the mechanical properties.

In this study, a series of heat treatment routes were designed based on the phase relations in IN718 and performed on the SPS-fabricated IN718 alloy. The mechanical properties of samples with different heat treatment were evaluated, and the results were related to the phase characterization. The microstructural evolution of the SPS IN718 alloy was also studied within the steps of sintering and heat treatment. It appears that the SPS IN718 shows a distinctive microstructure and its strength can be tuned by post-process heat treatment.

\section{Experimental Procedures}

The Inconel 718 powder (Sino-Euro Materials Technologies of Xi'an Co., Ltd., Xi'an, China) manufactured by the plasma rotation electrode process (PREP) was used as the starting material. The Inconel 718 powders are spherical with a diameter of $15-53 \mu \mathrm{m}$. The elemental composition of the powder was determined by inductive coupled plasma (ICP) analysis, as presented in Table 1 . The Inconel 718 alloy was fabricated using a SPS system (model HD-10 from FCT Germany, Gewerbepark, Germany) at a temperature of $1200{ }^{\circ} \mathrm{C}$, soaking for $10 \mathrm{~min}$ under $51 \mathrm{MPa}$ pressure. The detailed sintering parameters can be seen in our previous work [15]. The post-process heat treatments were conducted according to the following routes: (1) direct aging $\left(720^{\circ} \mathrm{C}, 8 \mathrm{~h} /\right.$ furnace cooling at $50{ }^{\circ} \mathrm{C} / \mathrm{h}$ to $620^{\circ} \mathrm{C}$, $8 \mathrm{~h} /$ air cooling) (designated as DA); (2) solution treatment conducted at $950{ }^{\circ} \mathrm{C}(1 \mathrm{~h} /$ air cooling $)+$ double aging $\left(720{ }^{\circ} \mathrm{C}, 8 \mathrm{~h} /\right.$ furnace cooling at $50{ }^{\circ} \mathrm{C} / \mathrm{h}$ to $620^{\circ} \mathrm{C}, 8 \mathrm{~h} /$ air cooling) according to the AMS 5663 standards [26] for wrought IN718 (designated as 950AC+aging); (3) solution treatment conducted at $1000{ }^{\circ} \mathrm{C}(1 \mathrm{~h} /$ air cooling) + double aging (same as the $950 \mathrm{AC}$ +aging samples) (designated as 1000AC+aging); and (4) solution treatment conducted at $1080^{\circ} \mathrm{C}(1 \mathrm{~h} /$ air cooling $)+$ double aging (same as the 950AC+aging samples; designated as 1080AC+aging). The schematic illustrations of SPS and heat treatment cycles are shown in Figure 1.

For observing and analyzing the microstructures, samples were ground by $\mathrm{SiC}$ paper and polished with a $3 \mu \mathrm{m}$ diamond suspension. The Kalling reagent $(100 \mathrm{~mL}$ ethanol, $100 \mathrm{~mL}$ hydrochloric acid, and $5 \mathrm{~g}$ copper chloride) was used as the etching solution. A scanning electron microscope 
(SEM, JSM-6900F, JEOL, Tokyo, Japan), equipped with energy dispersive X-ray spectroscopy (EDS) was used to complete the microstructure characterization of the IN718 powder and fabricated alloys. Thin foil samples were prepared by mechanical thinning followed by ion milling at room temperature and were analyzed by the transmission electron microscope (TEM, JEM-2100, Tokyo, Japan). Phase constituents of the IN718 samples were analyzed based on the X-ray diffraction (XRD, X' pert pro, PANalytical B. $\mathrm{V}$., Almelo, the Netherlands) results. The $\mathrm{Cu} \mathrm{K}$-alpha radiation was used, and the Bragg angles were selected from $30^{\circ}$ to $80^{\circ}$ with a scanning rate of $5^{\circ}$ per minute.

Table 1. The chemical composition of the plasma rotation electrode process (PREP)-processed Inconel 718 powder.

\begin{tabular}{ccccccccccccc}
\hline Element & $\mathbf{N i}$ & $\mathbf{C r}$ & $\mathbf{N b}$ & $\mathbf{M o}$ & $\mathbf{T i}$ & $\mathrm{Al}$ & $\mathbf{C o}$ & $\mathbf{M n}$ & $\mathrm{Si}$ & $\mathbf{C u}$ & $\mathbf{C}$ & $\mathbf{F e}$ \\
\hline Wt.\% & 54.28 & 17.97 & 5.12 & 3.00 & 0.98 & 0.57 & 0.21 & 0.09 & 0.077 & 0.069 & 0.024 & Bal. \\
\hline
\end{tabular}

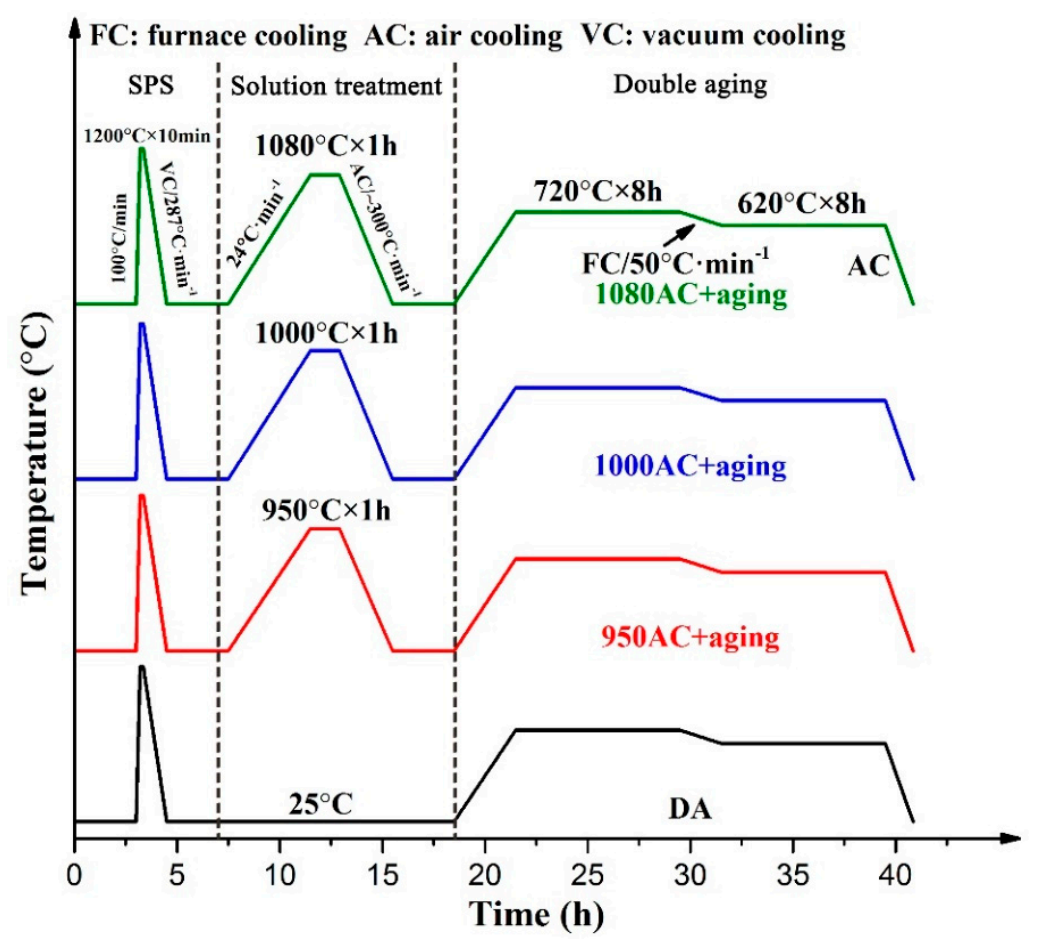

Figure 1. Schematic illustrations of spark plasma sintering (SPS) and the heat treatment cycles performed in this study.

The average Vickers hardness values were obtained with at least ten indentations. A micro hardness tester (HVT-1000, Lanzhou Zhongke Kaihua Technology Development Co., Ltd., Lanzhou, China) was used to complete the hardness tests at both room temperature and $650^{\circ} \mathrm{C}$. For compressive tests, cylindrical samples with a diameter of $8 \mathrm{~mm}$ and height of $12 \mathrm{~mm}$, as is suggested in the ASTM E9-89a (2000) standard [27], were prepared by the electro-discharging machine. Compressive tests were conducted using an electrical universal material testing machine (WDW-200, Changchun Kexin Test Instrument Co., Ltd., Changchun, China) at a strain rate of $1.1 \times 10^{-3} \mathrm{~s}^{-1}$, and at least three samples were tested for each condition.

\section{Results}

\subsection{Microstructure of the IN718 Powder and the SPS IN718 Alloys}

Figure 2 shows the cross-sectional morphology of the IN718 powder and microstructures of the SPS IN718 alloys. The microstructure of the IN718 powder (see Figure 2a) showed the dendritic grains, 
which was caused by the solidification partition coefficient difference of element compositions during the rapid cooling step of powder manufacturing. The powder EDS results, shown in Figure 2c,d, indicate that $\mathrm{Nb}$ and $\mathrm{Ti}$ segregated more severely in the interdendritic region than at the center of the dendrites. Meanwhile, $\mathrm{Ni}$ and Fe were more prone to aggregating in the dendrite cores. The microstructure of the as-fabricated (AF) samples (see Figure 2e) contained some block-shaped and bar-shaped segregation. It should be noted that the segregation constitutes a dendritic microstructure, although the outline of the dendritic grains was discontinuous (as also can be seen in Figure 3a). In order to confirm the element types in the segregation, the elemental map of EDS testing was conducted on the as-fabricated samples. As shown in Figure 3, Ni and Fe mainly segregated in the dendrite arms, while $\mathrm{Nb}$ and $\mathrm{Ti}$ segregated more severely in the interdendritic region. Moreover, the $\mathrm{Cr}$ element segregated in both block-shaped segregation and the dendrite arms. For the DA samples (see Figure 2f), the micro-segregations were not totally removed, because of the lack of the solution treatment. As shown in Figure $2 \mathrm{~g}-\mathrm{i}$, the microstructures of the solution-treated samples became more uniform, indicating that the elements diffused evenly into the matrix after solution treatment. The grain sizes of the SPS IN718 were measured by the Heyn linear intercept procedure in no less than three fields for each sample according to the ASTM E112 standard [28]. For the AF, DA, 950AC+aging, 1000AC+aging, and 1080AC+aging samples, the average grain sizes were $\sim 10 \mu \mathrm{m}, \sim 9.1 \mu \mathrm{m}, \sim 11 \mu \mathrm{m}$, $\sim 13.8 \mu \mathrm{m}$, and $\sim 20.4 \mu \mathrm{m}$, respectively. It should be noted that the average grain size of 1080AC+aging samples was much larger than that of other samples.
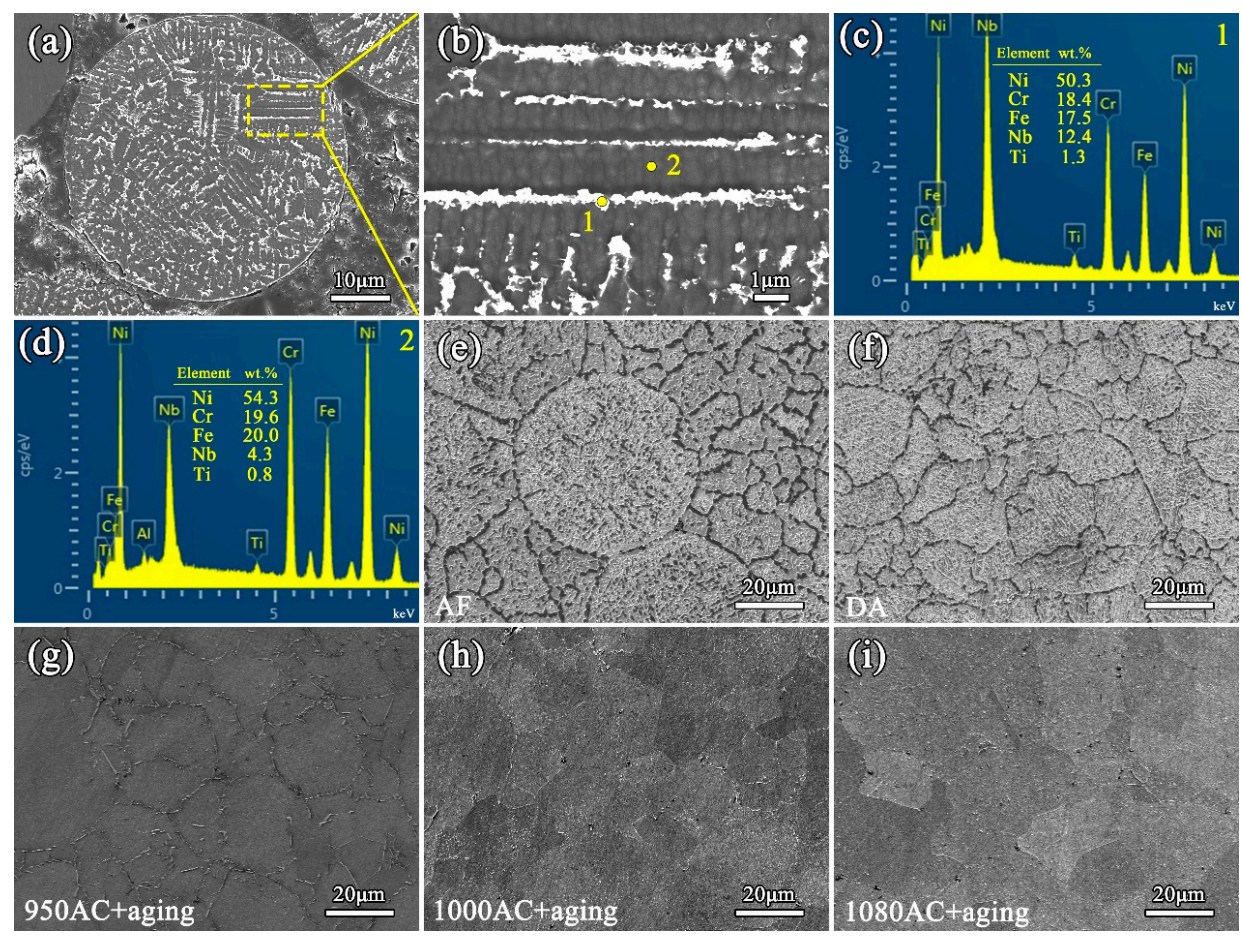

Figure 2. (a) Cross-sectional morphology of the IN718 powder. (b) The enlarged view of the powder microstructure in the region marked in (a). (c,d) Energy disperse spectroscopy (EDS) spectra and elemental contents of location 1 and 2 (marked in (b)), respectively. (e-i) Microstructures of the as-fabricated, direct aging (DA), 950AC+aging, 1000AC+aging, and 1080AC+aging samples.

Figure 4 presents the high-magnification SEM images of the SPS IN718 alloys. In the case of DA (see Figure 4a), the element segregation was inherited from the AF sample. As can be observed from the 950AC+aging samples (see Figure $4 \mathrm{~b}$ ), some minor phases precipitated along the grain boundaries. EDS analysis was carried out to identify these phases. Two types of precipitates were observed, the first one was block-shaped and rich in $\mathrm{Nb}$ and $\mathrm{C}$ (Figure 4e) and identified as the MC-carbide phases. The carbides mainly precipitated at grain boundaries, but could also be found in the grain 
interiors. The second type were precipitates that have a needle shape and are rich in $\mathrm{Ni}$ and $\mathrm{Nb}$ (see Figure 4f), identified as the $\delta-\mathrm{Ni}_{3} \mathrm{Nb}$ phase according to the phase characteristics of IN718 [29]. For the 1080AC+aging samples, the grain boundaries were free of the $\delta$ phase (Figure $4 \mathrm{~d}$ ) because the $1080^{\circ} \mathrm{C}$ exceeded the solvus of $\delta$ phase. However, the solution treatment temperatures in the present study were lower than the solvus of $\mathrm{NbC}$ (around $1250{ }^{\circ} \mathrm{C}$ [30]), and the carbide phases could not be totally removed from the microstructure.
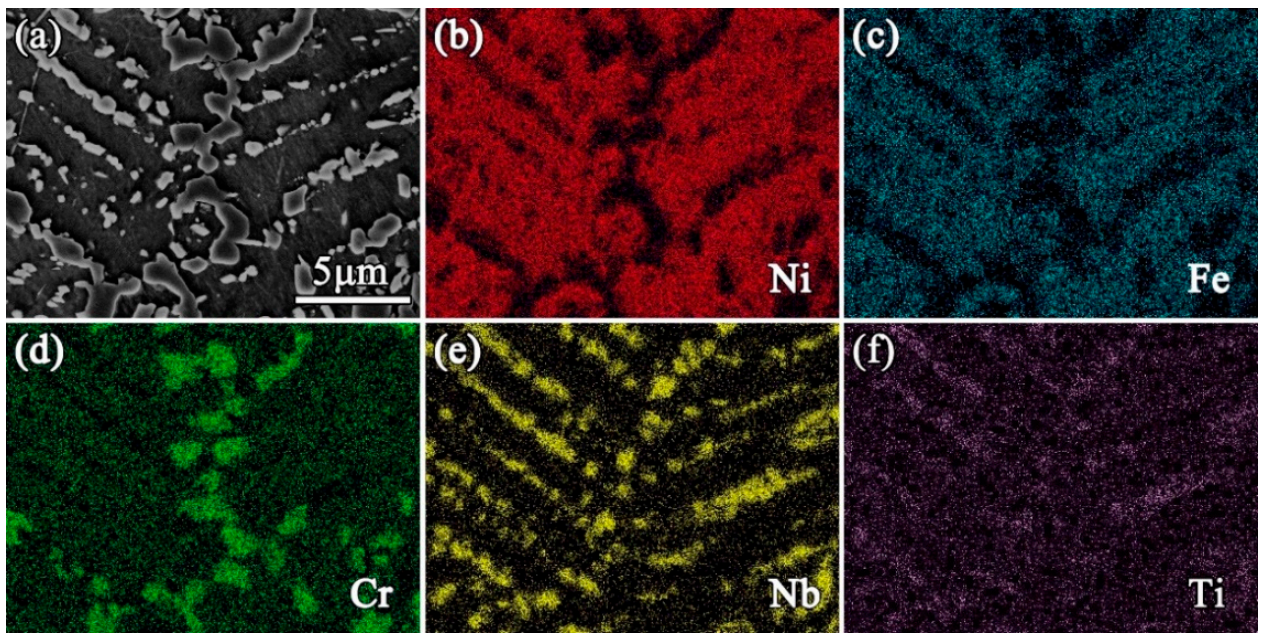

Figure 3. EDS elemental distribution of the as-fabricated sample: (a) SEM image of the tested field, (b) $\mathrm{Ni},(\mathbf{c}) \mathrm{Fe},(\mathbf{d}) \mathrm{Cr},(\mathbf{e}) \mathrm{Nb},(\mathbf{f}) \mathrm{Ti}$.
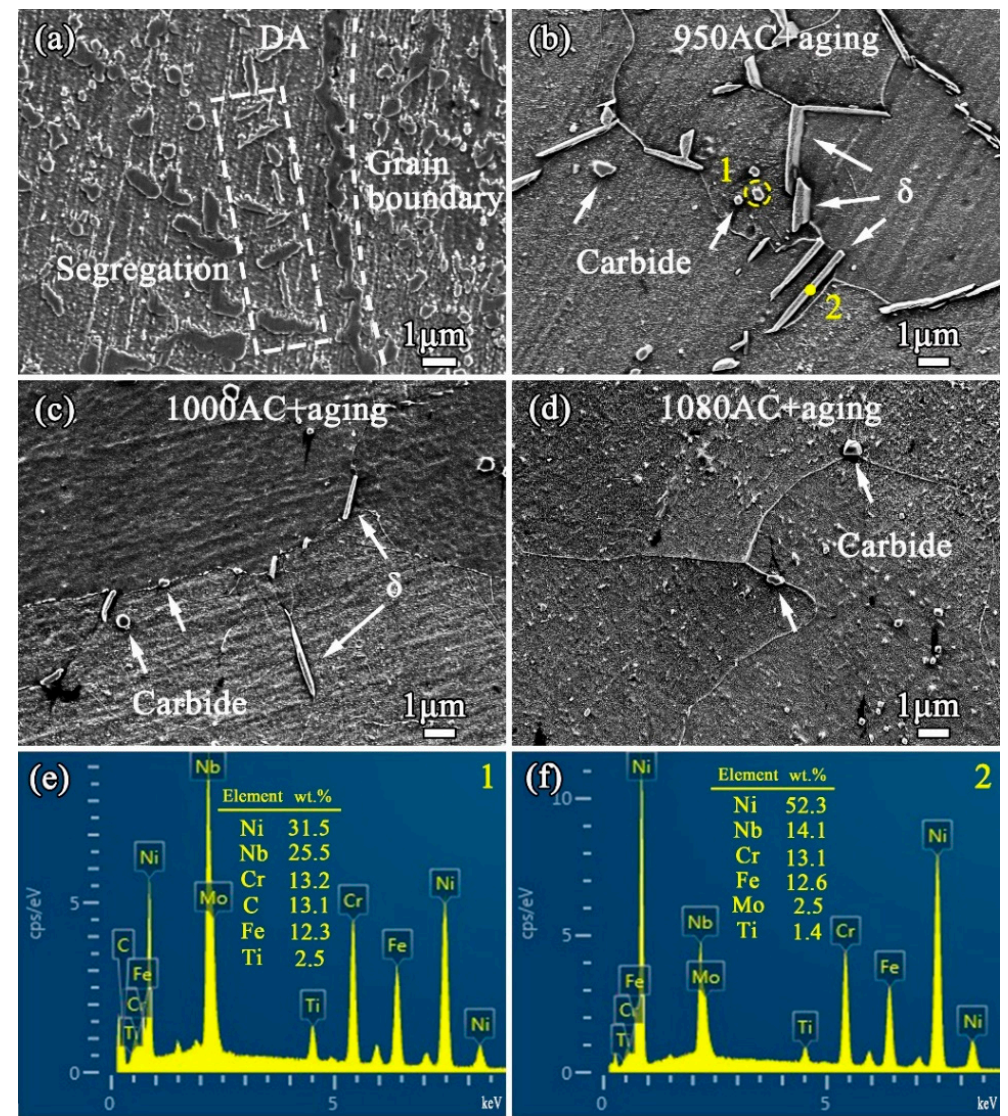

Figure 4. High-magnification scanning electron microscopy (SEM) micrographs of (a) DA, (b) 950AC+aging, (c) 1000AC+aging, and (d) 1080AC+aging samples. (e) and (f) are EDS spectra and elemental contents of the carbide and $\delta$ phases. 


\section{2. $X R D$ Analysis}

The X-ray diffraction (XRD) patterns of the as-fabricated and heat-treated IN718 alloys are presented in Figure 5. The diffraction peaks of $\gamma^{\prime}$ and $\gamma^{\prime \prime}$ phases could not be well distinguished because they overlapped with the peaks of the $\gamma$ matrix. The peaks of the carbide phase could be observed in the XRD results of the as-fabricated and directly aged samples. For the solution-treated and aged samples, the XRD patterns were similar to the DA and AF samples; however, the diffraction peaks of $\gamma$ matrix shifted to the lower angles. The XRD peak shifting may have been caused by the growing of the lattice parameters of the $\gamma$-matrix. During solution treatment, the elements such as $\mathrm{Nb}$ and Ti could be dissolved into the $\gamma$-austenite lattice. These foreign atoms generally existed in the interstitials of the $\gamma$-FCC lattice [31], causing the enlarging of the $\gamma$ lattice and leading to the XRD peak shifting. Because $\mathrm{Nb}$ and $\mathrm{Ti}$ are also the main carbide formation elements, the intensity of the XRD peaks representing the carbide phase became lower in the solution-treated samples.

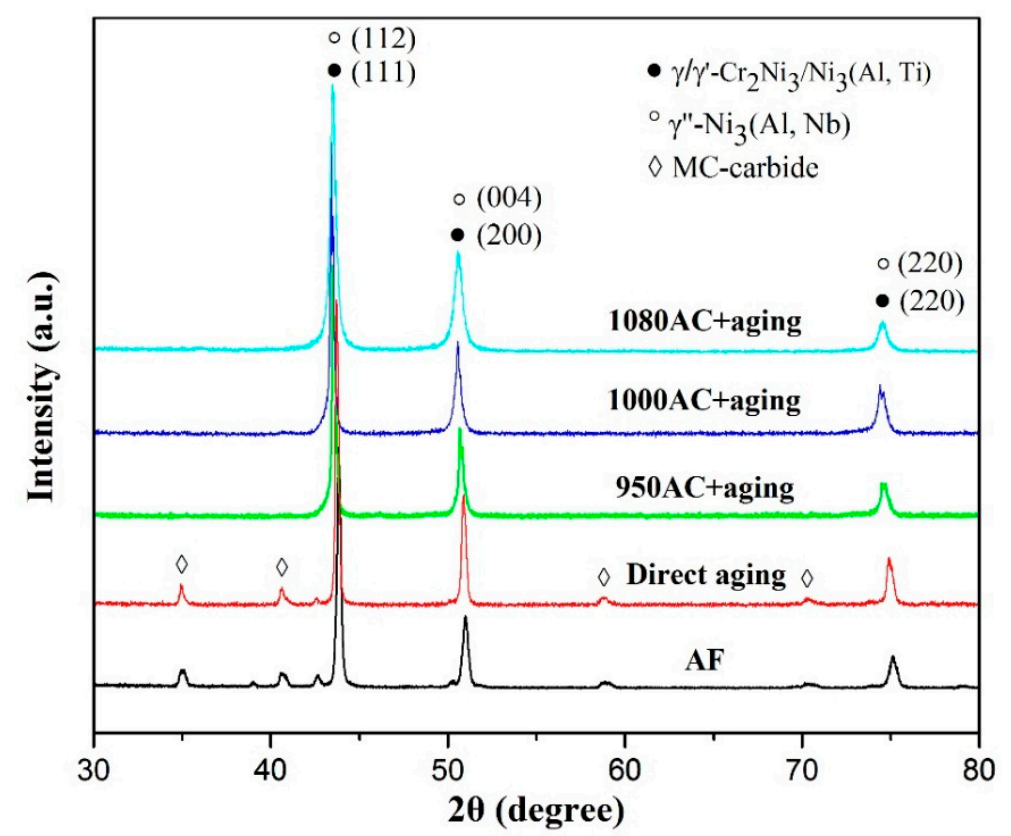

Figure 5. The X-ray diffraction (XRD) patterns of as-fabricated and heat-treated IN718 alloys.

As shown in the XRD patterns presented in Figure 5, the diffraction peaks of $\gamma, \gamma^{\prime}$, and $\gamma^{\prime \prime}$ phases could hardly be distinguished because the positions of diffraction peaks on the (111), (200), and (220) planes of $\gamma / \gamma^{\prime}$ phases were close to those on the (112), (004), and (220) planes of $\gamma^{\prime \prime}$. As a result, the precipitation behavior of $\gamma^{\prime \prime}$ and $\gamma^{\prime}$ phases needed to be analyzed by peak separation of the lower angle diffraction peaks on the (200) plane of $\gamma,(200)$ plane of $\gamma^{\prime}$, and (004) plane of $\gamma^{\prime \prime}$. The peak separation software, PeakFit for Windows [32], was used to complete the PXRD analysis by applying Gaussian fitting. The corresponding fitting results are shown in Figure 6. Based on the integral area of the separated peaks, the proportion of $\gamma^{\prime \prime}$ phase in the DA, 950AC+aging, 1000AC+aging, and 1080AC+aging samples was determined to be $40.4 \%, 29.4 \%, 35.6 \%$, and $19.1 \%$, respectively, while the contents of $\gamma^{\prime}$ phase were $18.3 \%, 10.0 \%, 10.4 \%$, and $37.2 \%$. According to the fitting results, the number of $\gamma^{\prime \prime}$ phase increased when solution-treated at $1000{ }^{\circ} \mathrm{C}$ and then dropped at $1080{ }^{\circ} \mathrm{C}$, whereas $\gamma^{\prime}$ phase precipitated at higher solution treatment temperatures. Moreover, $\gamma^{\prime \prime}$ and $\gamma^{\prime}$ phases presented their maximum precipitation tendencies in the DA and 1080AC+aging samples, respectively.

The lattice parameters and misfit values calculated from the fitting results are listed in Table 2. For the SPS-fabricated IN718, the lattice parameters of the $\gamma$-matrix were larger than those of the $\gamma^{\prime}$ and $\gamma^{\prime \prime}$ precipitates. The lattice parameters of the $\gamma$-matrix increased with the elevation of solution treatment temperatures because more alloying elements diffused into the $\gamma$ lattice at higher temperatures, 
causing the lattice expansion. The lattice misfit is used to evaluate the strain state at the interfaces of phases, which greatly influences the high-temperature properties of superalloys. It is generally believed that in the high-temperature creep tests, a higher microstructure stability is expected when the misfit between phases is smaller $[33,34]$. Due to the expanding of $\gamma$ lattice, the misfits between $\gamma^{\prime \prime}$ and $\gamma$ became larger with increasing solution temperatures. In all heat-treated conditions, the misfit values of $\delta_{\gamma / \gamma^{\prime \prime}}$ were larger than the values of $\delta_{\gamma / \gamma^{\prime}}$ because of the different structures between $\gamma^{\prime \prime}$ (BCT) and $\gamma$ (FCC) phases. The minimum misfit values were observed for the DA samples, with a $\delta_{\gamma / \gamma^{\prime \prime}}$ and $\delta_{\gamma / \gamma^{\prime}}$ of approximately $0.32 \%$ and $0.08 \%$, respectively.
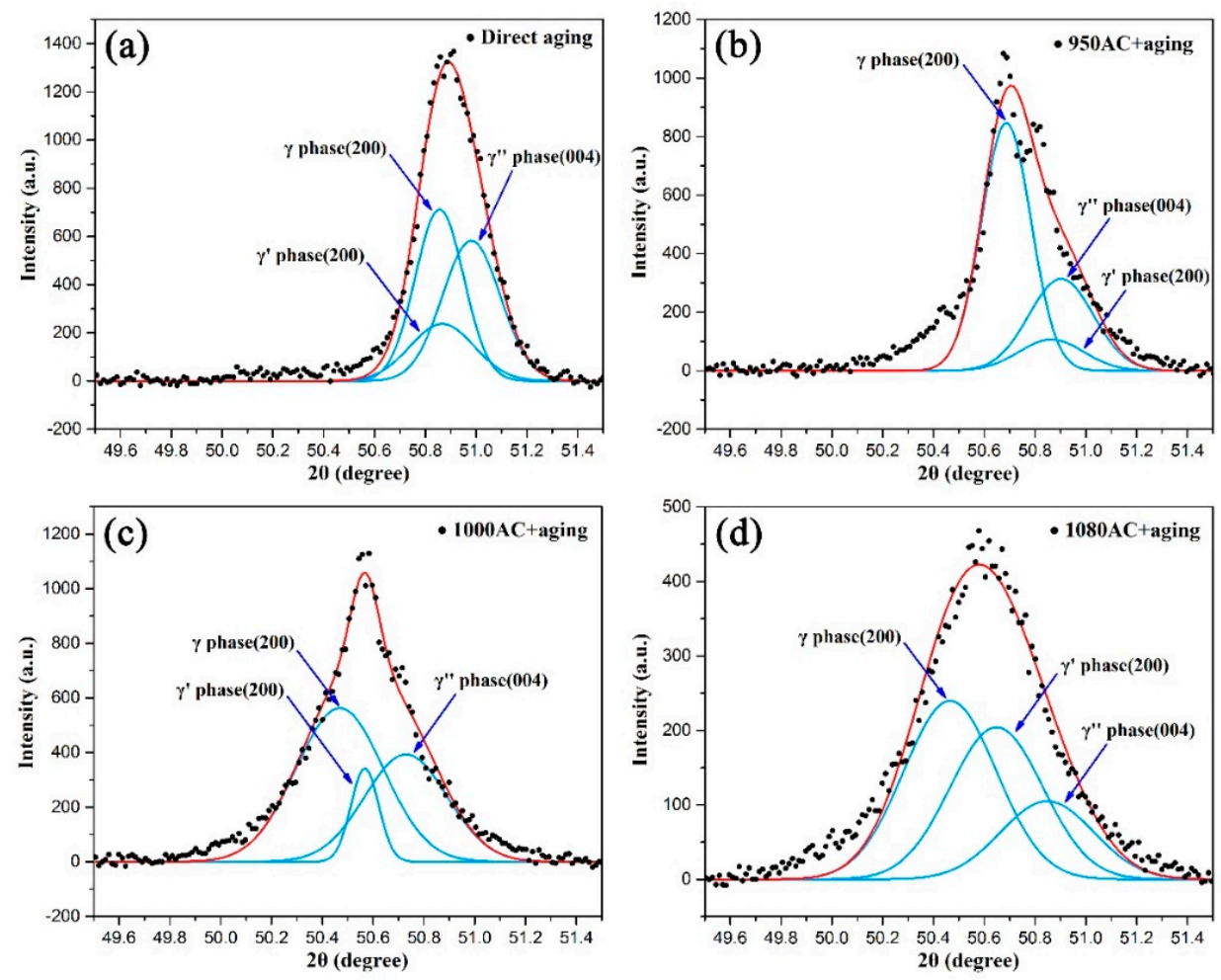

Figure 6. The powder X-ray diffraction (PXRD) patterns and corresponding Gaussian fitting results for the (a) DA, (b) 950AC+aging, (c) 1000AC+aging, and (d) 1080AC+aging samples.

Table 2. Lattice parameters (nm), and misfit values $\delta(\%)$ of $\gamma, \gamma^{\prime}$, and $\gamma^{\prime \prime}$ phases calculated on the basis of peak fitting of the XRD data.

\begin{tabular}{ccccc}
\hline Heat Treatment & Direct aging & 950AC+aging & 1000AC+aging & 1080AC+aging \\
\hline $\mathrm{a}_{\gamma}$ & 0.35907 & 0.36019 & 0.36163 & 0.36166 \\
$\mathrm{a}_{\gamma^{\prime}}$ & 0.35904 & 0.35899 & 0.36097 & 0.36044 \\
$\mathrm{a}_{\gamma^{\prime \prime}}$ & 0.35761 & 0.35874 & 0.35877 & 0.35882 \\
$\mathrm{c}_{\gamma^{\prime \prime}}$ & 0.71648 & 0.71834 & 0.71983 & 0.71821 \\
$\delta_{\gamma / \gamma^{\prime}}$ & 0.08412 & 0.33384 & 0.18254 & 0.33868 \\
$\delta_{\gamma / \gamma^{\prime \prime}}$ & 0.32121 & 0.34511 & 0.63827 & 0.75209 \\
\hline
\end{tabular}

\subsection{TEM Observation of the SPS IN718 Alloys}

The TEM results of the SPS IN718 alloys are shown in Figure 7. No obvious $\gamma^{\prime \prime} / \gamma^{\prime}$ phase was observed in the bright field TEM image of the as-fabricated samples (see Figure 7a), but some dislocations could be identified in the $\gamma$-matrix. The corresponding selected area electron diffraction (SAED) image of the AF sample (see the inset in Figure 7a) only showed the pattern of the $\gamma$-matrix. Figure $7 b-d$ shows the morphology of the nano-scale precipitates in the DA, 950AC+aging, and 1000AC+aging samples, respectively. At least three TEM images for each sample were used to calculate the 
volume fraction of $\gamma^{\prime \prime}$ phase by using the image analysis software, ImageJ (Version 1.52J, Bethesda Softworks, Rockville, MD, USA) [35]. The results showed that the volume fractions of $\gamma^{\prime \prime}$ phase in DA, 950AC+aging, and 1000AC+aging samples were $23.7 \%, 5.0 \%$, and $23.2 \%$, respectively. In the DA samples (see Figure 7b), large amounts of disc-shaped $\gamma^{\prime \prime}$ phase precipitated along two directions. The length of the $\gamma^{\prime \prime}$ phase precipitated in the DA samples was about 25 32 nm, which was nearly the same size as that of $\gamma^{\prime \prime}$ in the solution-treated and aged samples. Due to the precipitation of $\gamma^{\prime}$ and the three variants of $\gamma^{\prime \prime}$ in the $\gamma$ matrix during aging treatment, the nano-scale of those precipitates and their structures resulted in the overlapping of SAED patterns at specific orientations. As marked in the SAED patterns of DA samples (see the inset in Figure 7b), spot 1 and 5 could arise from (010) and (100) of [001] $\gamma^{\prime}$ and from (002) of $\gamma^{\prime \prime}$ (along the [010] or [100] axis). Spot 2 and 4 belong to the (1/2 10) and (1 1/2 0) planes of $\gamma^{\prime \prime}$ phase, respectively. The superlattice reflection of (110) (along the [001] axis) for $\gamma^{\prime}$ and $\gamma^{\prime \prime}$ have remarkable coincidence at spot 3 . The SAED patterns for DA samples were similar to the TEM results of Inconel 718 alloys reported in literature [36-38].
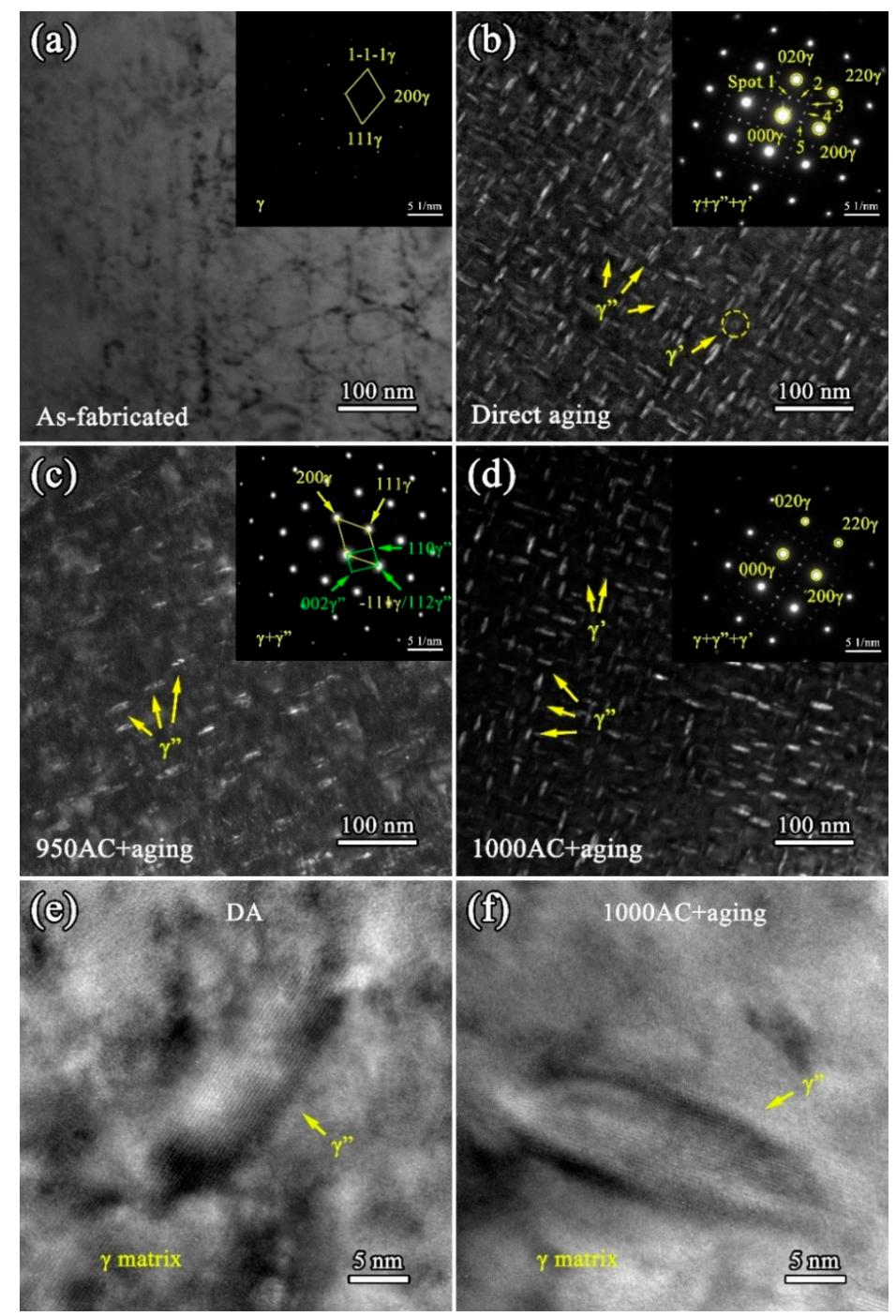

Figure 7. The transmission electron microscopy (TEM) microstructures of the SPS IN718 alloys: (a) the bright field (BF) TEM image displays the $\gamma$-matrix of the as-fabricated samples (the inset shows the corresponding selected area electron diffraction (SAED) pattern); (b), (c), and (d) show the morphology of the precipitates in the DA, 950AC+aging, and 1000AC+aging samples, respectively (the insets are their corresponding SAED patterns). (e,f) High resolution (HR)-TEM images of the $\gamma^{\prime \prime}$ phases in DA and 1000AC+aging samples. 
As shown in Figure 7c, the content of $\gamma^{\prime \prime}$ phase in the 950AC+aging samples (5.0 vol\%) was much lower than that in the DA samples $(23.7 \mathrm{vol} \%)$. The SAED patterns of the 950AC+aging samples (see the inset in Figure 7c) failed to recognize the $\gamma^{\prime}$ phase, possibly owing to its low amount. As reported in the Ref. $[39,40], \gamma^{\prime}$ phase is more likely to precipitate when solution-treated at higher temperatures (generally above $1150^{\circ} \mathrm{C}$ ). The SAED patterns of $950 \mathrm{AC}+$ aging samples in this study were similar to the TEM results of the electron beam melted (EBMed) IN718 alloys that were solution-treated at $980{ }^{\circ} \mathrm{C}$ [39]. When elevating the solution treatment temperature to $1000{ }^{\circ} \mathrm{C}$, more $\gamma^{\prime \prime} / \gamma^{\prime}$ phases precipitated in the alloy compared with 950AC+aging samples. It is because more alloying elements (such as $\mathrm{Nb}$, $\mathrm{Al}$ and $\mathrm{Ti}$ ) were dissolved into the matrix, and a higher supersaturation degree was achieved at $1000{ }^{\circ} \mathrm{C}$, which is beneficial for the precipitating of $\gamma^{\prime \prime} / \gamma^{\prime}$ phases during aging. The SAED patterns of 1000AC+aging (see the inset in Figure 7d) samples were in high accordance with those of the DA samples. Figure 7e,f shows the high-resolution TEM (HR-TEM) images of DA and 1000AC+aging samples, which indicates that the $\gamma^{\prime \prime}$ phases maintained a perfectly coherent structure with the $\gamma$ matrix in the SPS IN718 alloy.

\subsection{Mechanical Properties}

\subsubsection{Vickers Hardness}

In order to evaluate the high-temperature resistance of the SPS-fabricated IN718 alloys, the Vickers hardness tests were conducted at both room temperature (RT) and $650{ }^{\circ} \mathrm{C}$. Figure 8 shows the average hardness values and the errors obtained with at least 10 indentations for each sample. The hardness values of AF samples were much lower than the heat-treated samples, mainly due to the free of $\gamma^{\prime \prime} / \gamma^{\prime}$ phases. The maximum hardness value was obtained by DA samples at both RT and $650{ }^{\circ} \mathrm{C}$. Compared with the 950AC+aging samples, the hardness of 1000AC+aging samples increased because of the larger content of $\gamma^{\prime \prime} / \gamma^{\prime}$ precipitates. The hardness of 1080AC+aging samples showed an obvious drop mainly caused by the grain coarsening during the solution treatment. The hardness trend at $650{ }^{\circ} \mathrm{C}$ was consistent with that at RT. As presented in Figure 8, the micro-hardness decreased for all samples when tested at $650{ }^{\circ} \mathrm{C}$. Such hardness reduction is caused by the thermal softening effect commonly observed in alloys. However, the hardness reduction was within a limited value, indicating that the SPS-fabricated IN718 alloys maintained a good mechanical property at $650{ }^{\circ} \mathrm{C}$.

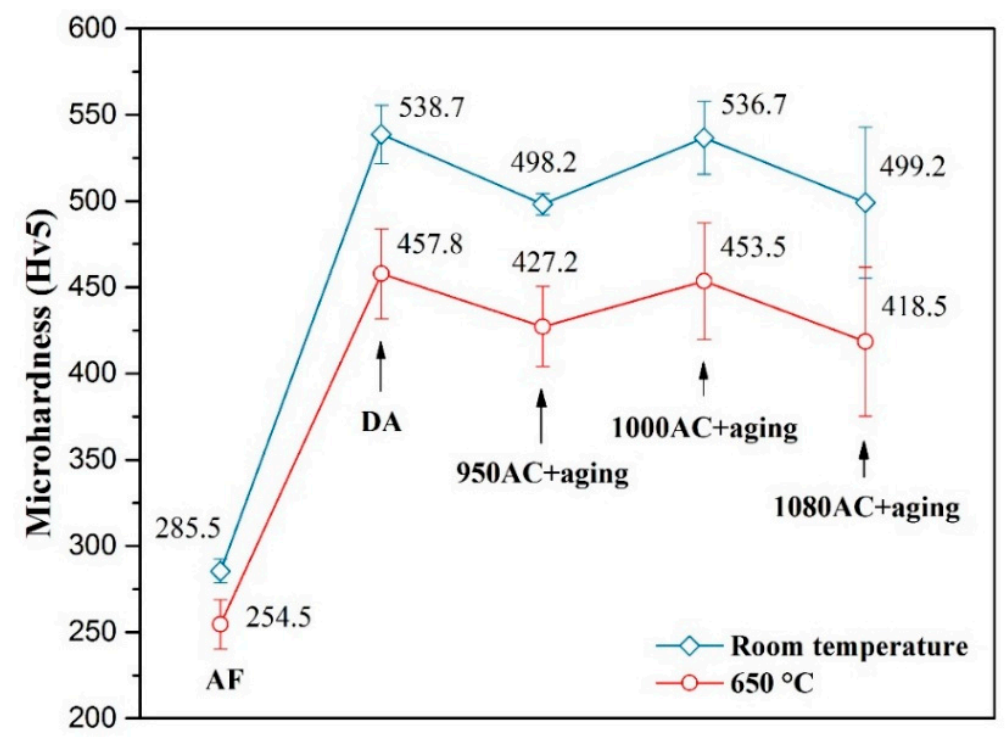

Figure 8. Vickers hardness of the SPS IN718 alloys at room temperature and $650{ }^{\circ} \mathrm{C}$. 


\subsubsection{Compressive Properties}

The representative stress-strain curves of the SPS IN718 alloys are illustrated in Figure 9a, while the $0.2 \%$ offset yield strength $\left(\sigma_{0.2}\right)$ and the ultimate compressive strength $\left(\sigma_{b}\right)$ are presented in Figure $9 \mathrm{~b}$. The average values of $\sigma_{0.2}, \sigma_{\mathrm{b}}$, Young's modulus and densities of the samples are listed in Table 3 . It should be noted that no obvious fracture failure was observed after the compressive tests of the SPS IN718 alloys. However, at about $48-57 \%$ of the strain, the stress grew slowly or decreased with the increase of strain in the stress-strain curves of the heat-treated samples. It was considered that during this stage, large amounts of cracks initiated and propagated across the samples surface. After this stage, the slopes of stress-strain curves changed obviously due to the work-hardening effect. Therefore, we took the corresponding stress values at the slowly-growing (or decreasing) stage as the ultimate compressive strength of the samples.

(a)

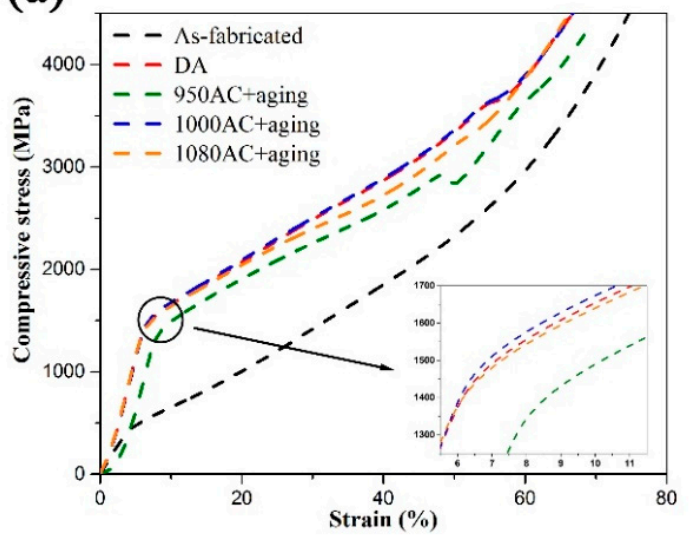

(b)

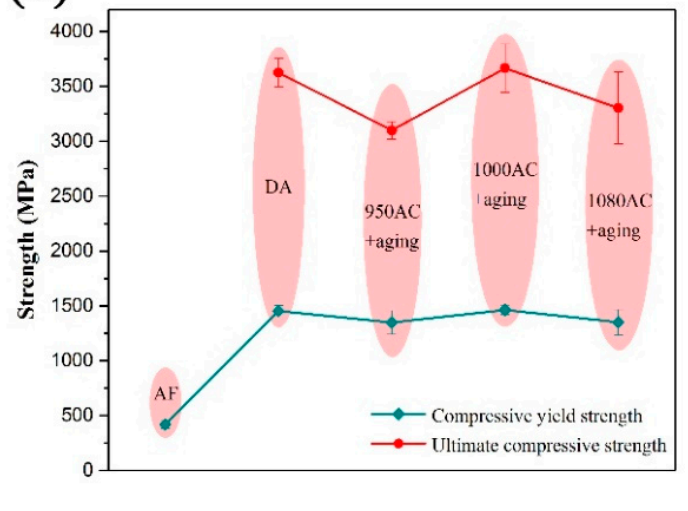

Figure 9. (a) The representative compressive stress-strain curves of the SPS IN718 alloys (the inset is the enlarged view of the yielding stage). (b) The compressive yield strength and ultimate compressive strength of the IN718 samples.

Table 3. Mechanical properties, densities and relative densities of the SPS IN718 alloys after different heat treatments.

\begin{tabular}{cccccc}
\hline Samples & $\boldsymbol{\sigma}_{\mathbf{0 . 2}} \mathbf{( M P a )}$ & $\boldsymbol{\sigma}_{\mathbf{b}} \mathbf{( M P a )}$ & $\begin{array}{c}\text { Young's Modulus } \\
\mathbf{( G P a )}\end{array}$ & $\begin{array}{c}\text { Density } \\
\mathbf{( g \cdot \mathbf { c m } ^ { - 3 } )}\end{array}$ & $\begin{array}{c}\text { Relative } \\
\text { Density (\%) }\end{array}$ \\
\hline As-fabricated & 419 & - & 13.83 & 7.66 & 93 \\
DA & 1454 & 3626 & 27.50 & 8.07 & 98 \\
950AC+aging & 1349 & 3100 & 24.80 & 8.15 & 99 \\
1000AC+aging & 1463 & 3666 & 26.55 & 8.16 & 99 \\
1080AC+aging & 1350 & 3303 & 26.18 & 8.20 & 99 \\
\hline
\end{tabular}

As shown in Figure 9, the yield strength of the as-fabricated samples was much lower than the heat-treated samples, which was consistent with the micro-hardness test results. After heat treatment, the compressive yield strength of the alloy improved significantly mainly due to the precipitating of $\gamma^{\prime \prime} / \gamma^{\prime}$ strengthening phases. The 1000AC+aging samples exhibited the highest $0.2 \%$ offset yield strength (1463 MPa) and ultimate compressive strength (3666 MPa). However, the 950AC+aging samples (heat-treated by the standard route) showed the minimum compressive properties in the heat-treated samples. Compared with the 950AC+aging samples, the $\sigma_{0.2}$ and $\sigma_{\mathrm{b}}$ values of $1000 \mathrm{AC}+$ aging samples increased by $\approx 9 \%$ and $\approx 18 \%$, while the $\sigma_{0.2}$ and $\sigma_{\mathrm{b}}$ values of DA samples were $\approx 8 \%$ and $\approx 17 \%$ higher. The compressive properties of 1080AC+aging samples were lower than the DA and 1000AC+aging samples, which could be ascribed to the larger grain sizes of 1080AC+aging samples. 


\section{Discussion}

\subsection{The Precipitating Mechanisms of $\gamma^{\prime \prime} / \gamma^{\prime}$ in the DA Condition}

As can be observed from Figure $7 \mathrm{~b}$, the $\gamma^{\prime \prime} / \gamma^{\prime}$ phases precipitated extensively in the DA samples. However, the precipitating mechanism of $\gamma^{\prime \prime} / \gamma^{\prime}$ phases in DA samples was different from that of the solution-treated samples. In the as-fabricated samples, $\gamma^{\prime \prime} / \gamma^{\prime}$ phases did not precipitate after SPS, as can be observed from Figure 7a. However, large numbers of $\gamma^{\prime \prime} / \gamma^{\prime}$ phases precipitated after direct aging treatment. This phenomenon can be explained by comparing the SPS cooling curve in this study with the IN718 TTT diagram [41]. As can be seen from Figure 10, the SPS cooling was very rapid and the cooling curve did not pass through the $\gamma^{\prime \prime} / \gamma^{\prime}$ precipitation zones. When SPS sintering at $1200{ }^{\circ} \mathrm{C}$, alloying elements were dissolved into the $\gamma$ matrix. During the fast cooling period of SPS, the dissolved elements did not have enough time to diffuse evenly or precipitate as secondary phases in the samples, and the AF samples obtained a supersaturated solid solution state after SPS. The following direct aging treatment activated the precipitation of $\gamma^{\prime \prime}$ and $\gamma^{\prime}$ phases. Combined with TEM results, the amount of $\gamma^{\prime \prime}$ and $\gamma^{\prime}$ in DA samples was considerably large. This is the main reason that high hardness and compressive strength were acquired by DA samples. By comparison with the DA samples, the solution-treated and aged samples were subjected to a second solution treatment, and the solubility of the alloying elements mainly depended on the solution treatment temperature. After air cooling, samples acquired the supersaturated solid solution state, which enabled the precipitating of strengthening phases in the following double-aging process.

The SPS cooling curve in this study.

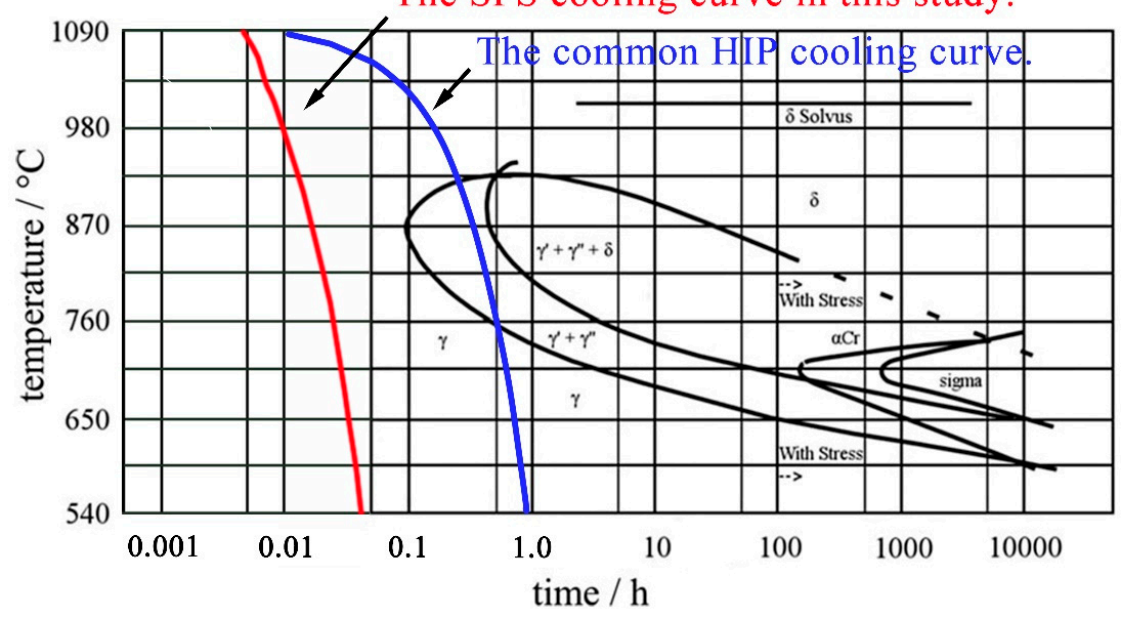

Figure 10. The time-temperature-transformation (TTT) diagram of IN718 alloy [41] with the SPS and hot-isostatic-pressing (HIP) cooling curves.

The blue curve in Figure 10 shows the frequently used hot-isostatic-pressing (HIP) cooling rate of $10^{\circ} \mathrm{C} / \mathrm{min}$ (close to the cooling speed limit of HIP). It can be seen that the HIP cooling curve goes straight into the $\gamma^{\prime \prime} / \gamma^{\prime}$ zones due to the lower cooling rate than SPS. As reported in the literature [18,42], for the HIP-fabricated IN718 alloy, $\gamma^{\prime \prime} / \gamma^{\prime}$ phases already precipitated in the samples before heat treatment. The precipitation of the $\gamma^{\prime \prime} / \gamma^{\prime}$ phases in as-fabricated samples led to the release of the matrix supersaturation. When directly aging the HIPed IN718, only the pre-existing $\gamma^{\prime \prime} / \gamma^{\prime}$ precipitations grew and coarsened; new $\gamma^{\prime \prime} / \gamma^{\prime}$ could not precipitate due to the low driving force for their nucleation. Similar situations can also be found in the IN718 alloys prepared by electron beam melting (EBM) [12,43] and selective laser melting (SLM) [14] methods. For the HIPed IN718, the mechanical properties of DA samples are inferior to the solution-treated samples. In this study, the hardness of SPS-fabricated IN718 in DA condition was higher than the solution-treated samples. In addition, the compressive properties of DA samples were comparable to the best one in the solution-treated and aged samples. 
This indicates that DA is the optimized heat treat route for SPS-fabricated IN718 alloys because it ensures the excellent mechanical properties and reduces the heat treatment steps.

\subsection{The Relations of the Microstructure and Mechanical Properties}

After heat treatment, the hardness and compressive properties increased significantly, mainly because of the precipitation of $\gamma^{\prime \prime}$ and $\gamma^{\prime}$ phases during aging. However, the precipitation of $\delta$ and carbide phases can greatly influence the precipitation behavior of $\gamma^{\prime \prime} / \gamma^{\prime}$ phases and thus also the mechanical properties. It should be noted that the $\delta-\mathrm{Ni}_{3} \mathrm{Nb}$ phase shares the same elemental compositions with $\gamma^{\prime \prime}$ phase, and $\gamma^{\prime \prime}$ phase can transform into $\delta$ during heat treatment $[8,9,29]$. At a given concentration of $\mathrm{Nb}$, the precipitation of $\delta$ phase will consume $\mathrm{Nb}$ atoms, resulting in the decrease of the $\gamma^{\prime \prime}$ content. As reported in the literature [13], large numbers of $\delta$ phase precipitated in the alloy are detrimental for sample mechanical properties because it competes $\mathrm{Nb}$ elements with $\gamma^{\prime \prime}$ phase. Meanwhile, appropriate amounts of $\delta$ at grain boundaries can restrain the grain growth, which is beneficial for enhancing the mechanical properties [11,12]. For the 950AC+aging samples, the content of $\delta$ phases was large (see Figure 4) and their sizes were larger than those in the $1000 \mathrm{AC}+$ aging samples. This is because the precipitation rate for $\delta$ phase is the highest at around $900{ }^{\circ} \mathrm{C}$ [44]. Owing to the considerable quantities of $\mathrm{Nb}$ elements consumed by the $\delta$ phase, less $\gamma^{\prime \prime}$ phase precipitated in 950AC+aging samples (see Figure 7c), resulting in the inferior mechanical properties. With the aim of promoting the formation of $\gamma^{\prime \prime}$ and limiting the amount of $\delta$ phase, we elevated the solution annealing temperature to $1000^{\circ} \mathrm{C}$. As a result, both the amount and length of $\delta$ phase were reduced in $1000 \mathrm{AC}+$ aging samples (see Figure 4). The $\gamma^{\prime \prime}$ phases in the 1000AC+aging samples were obviously denser than those in the 950AC+aging samples (see Figure 7c,d), which directly enhanced the sample hardness and compressive strength. Moreover, when solution-treated at $1000{ }^{\circ} \mathrm{C}$, more alloying elements could diffuse into the matrix lattice, which is thermo-dynamically favorable for precipitating $\gamma^{\prime \prime} / \gamma^{\prime}$ phases. In the 1080AC+aging samples, no needle-shaped $\delta$ phase could be found because $1080^{\circ} \mathrm{C}$ exceeds the solvus of $\delta$ phase (around $1050{ }^{\circ} \mathrm{C}$ [11]). Consequently, grain growth could not be restricted by the grain boundary $\delta$ phases. Therefore, the coarsening of grains is possibly the main reason for the inferior mechanical performance of 1080AC+aging samples. The DA regime activates the precipitation of large amounts of $\gamma^{\prime \prime} / \gamma^{\prime}$ phases and avoids the grain growth caused by solution annealing. Therefore, a novel mechanical property can be achieved by DA, and it seems that the solution treatment is abundant for the SPS-fabricated IN718 alloy.

In the present work, both the sintering and heat treatment temperatures do not exceed the solvus of $\mathrm{NbC}$ (around $1250^{\circ} \mathrm{C}$, as mentioned above); thus, blocky carbide phases could not be removed from the IN718 samples (see Figure 4). Generally, the existence of carbides is harmful for the mechanical properties of the sample because carbides can easily cause stress concentration near the tips and become the crack initiation site [18]. However, it is also reported that the formation of carbides at grain boundaries is preferred because they can improve the grain boundary strength by inhibiting the movement of dislocations [13]. Moreover, carbides can restrain the grain growth by the pinning effect, which is beneficial for improving sample mechanical properties [45]. According to existing literature, the role of carbides has proved controversial. Besides, the low carbon content in IN718 suggests that only a small number of carbide phases can be formed in the samples. Therefore, it is considered that the existence of carbide phase has a minor influence on the sample mechanical properties.

\subsection{Microstructural Evolution during SPS and Heat Treatment}

As mentioned above, in the IN718 powder, the segregation of $\mathrm{Nb}$ and Ti caused the dendritic microstructure (see Figure 2a,g-i). The microstructure of the as-fabricated samples showed the dendritic segregation with discontinuous outlines (see Figure 3a). The EDS element distribution map (Figure 3) showed that element types $(\mathrm{Nb}$ and $\mathrm{Ti}$ ) segregated in the interdendritic regions of the as-fabricated samples were the same as those segregated in the IN718 powder. Moreover, the average secondary dendrite arm spaces (SDAS) of the powder and the SPS-fabricated IN718 alloy were almost the same 
(1.64 $\mu \mathrm{m}$ and $1.66 \mu \mathrm{m}$, respectively). As reported in Ref. [13,46-49], the micro-segregation of Nb, Mo, and Ti elements in the interdendritic region is very common in the cast, wrought, and P/M IN718. After solution treatment and aging, the segregated elements diffused evenly into the sample matrix. Based on the sample characterization results and the discussions above, the microstructural evolution of the SPS IN718 is schematically illustrated in Figure 11. The first image of the schematics shows that $\mathrm{Nb}$ and Ti elements initially segregated in the interdendritic region of the raw powder due to the solidification partition coefficient difference of the alloying elements. Then, the element segregation was reduced by SPS sintering the powder compact at $120{ }^{\circ} \mathrm{C}$ for $10 \mathrm{~min}$. However, due to the SPS soaking time being too short, the dendritic segregation was not totally eliminated and became discontinuous in the as-fabricated samples. Lastly, the homogenization effect of solution treatment promoted the alloy elements to diffuse evenly into the matrix. The final microstructure of the solution-treated and aged samples mainly contains the $\gamma$-matrix and $\gamma^{\prime \prime}$ phases.

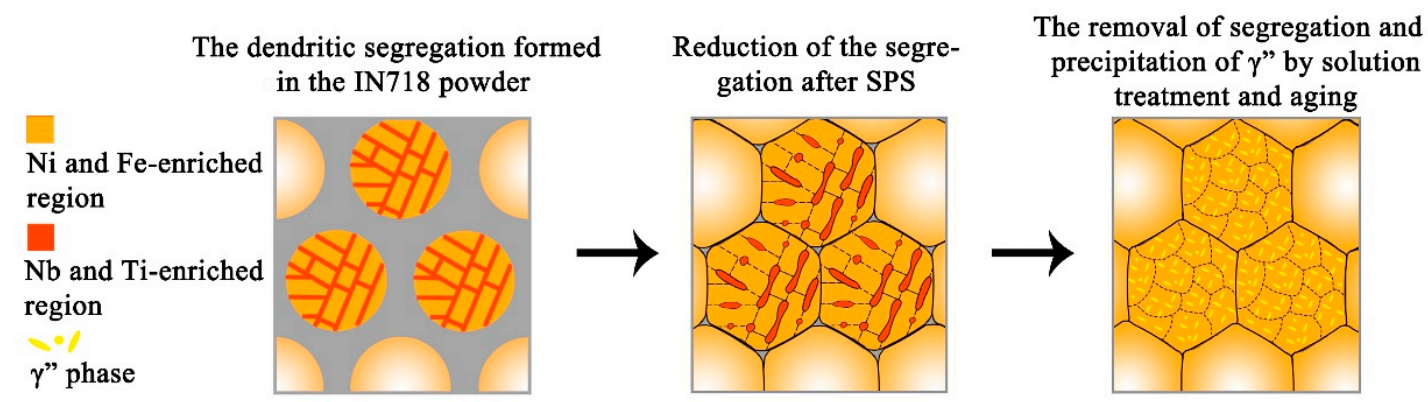

Figure 11. Schematic illustration of the microstructural evolution of SPS IN718 alloy during sintering and heat treatment.

\section{Conclusions}

In this study, the SPS technology was employed to prepare the IN718 alloy, and the effects of post heat treatment on the microstructural evolution, phase transformation and mechanical properties of SPS IN718 alloys were studied. The conclusions drawn are as follows:

1. Direct aging promotes the full precipitation of $\gamma^{\prime \prime} / \gamma^{\prime}$ phases and reduces the heat treatment steps, which is considered as the optimal heat treatment regime for the SPS-fabricated IN718 alloy. Compared with the samples heat-treated by the standard route of as-cast IN718, both hardness and compressive properties of the DA samples showed obvious enhancement.

2. The microstructural evolution of the SPS IN718 was ascribed to the reduction of elemental segregation during SPS and heat treatment. The post-sintering heat treatment tailored the phase compositions in the alloy, and thus mechanical properties were enhanced by this method. The SPS IN718 alloys exhibited excellent high-temperature resistance at $650{ }^{\circ} \mathrm{C}$.

3. In addition, the method provided herein is an efficient and economic process for enhancing the mechanical properties of the SPS IN718 alloy, which was achieved by the direct aging regime. The DA samples have comparable strength with the best one of the solution-treated and aged samples. The approach can provide potential guidance for improving mechanical properties in other precipitation strengthening alloys by excluding the energy-intensive solution treatment.

Author Contributions: S.Y. wrote the paper; G.C. conceived and designed the experiments; S.Y. and Y.W. performed the experiments; Q.W. and G.C. analyzed the data; C.Z. reviewed and edited the manuscript; D.C. supervised the whole research work.

Funding: This work was supported by the Sichuan Education Reform Project (No. JG2018-158) and National Natural Science Foundation of China (Grant Nos. 51601156, 51675445, 51601117 and U1537201).

Acknowledgments: The authors also thank Hongtao Chen for his help with the TEM characterization.

Conflicts of Interest: The authors declare no conflict of interest. 


\section{References}

1. Li, L.; Gong, X.; Ye, X.; Teng, J.; Nie, Y.; Li, Y.; Lei, Q. Influence of Building Direction on the Oxidation Behavior of Inconel 718 Alloy Fabricated by Additive Manufacture of Electron Beam Melting. Materials 2018, 11, 2549. [CrossRef] [PubMed]

2. Moussaoui, K.; Rubio, W.; Mousseigne, M.; Sultan, T.; Rezai, F. Effects of Selective Laser Melting additive manufacturing parameters of Inconel 718 on porosity, microstructure and mechanical properties. Mater. Sci. Eng. A 2018, 735, 182-190. [CrossRef]

3. Hua, Y.; Liu, Z. Experimental Investigation of Principal Residual Stress and Fatigue Performance for Turned Nickel-Based Superalloy Inconel 718. Materials 2018, 11, 879. [CrossRef] [PubMed]

4. Calandri, M.; Manfredi, D.; Calignano, F.; Ambrosio, E.P.; Biamino, S.; Lupoi, R.; Ugues, D. Solution Treatment Study of Inconel 718 Produced by SLM Additive Technique in View of the Oxidation Resistance. Adv. Eng. Mater. 2018, 20, 1800351. [CrossRef]

5. Zhang, H.; Li, C.; Guo, Q.; Li, H.; Liu, Y. Deformation Mechanism of L12- $\gamma^{\prime}$ Phase in Bimodal $\gamma^{\prime \prime}-\gamma^{\prime}$ Precipitation Hardened Inconel 718 Superalloy. Adv. Eng. Mater. 2018, 20, 1800652. [CrossRef]

6. Ma, W.; Xie, Y.; Chen, C.; Fukanuma, H.; Wang, J.; Ren, Z.; Huang, R. Microstructural and mechanical properties of high-performance Inconel 718 alloy by cold spraying. J. Alloys Compd. 2019, 792, $456-467$. [CrossRef]

7. Lin, Y.C.; Yin, L.-X.; Luo, S.-C.; He, D.-G.; Peng, X.-B. Effects of Initial $\delta$ Phase on Creep Behaviors and Fracture Characteristics of a Nickel-Based Superalloy. Adv. Eng. Mater. 2018, 20, 1700820. [CrossRef]

8. Zhang, H.; Li, C.; Liu, Y.; Guo, Q.; Huang, Y.; Li, H.; Yu, J. Effect of hot deformation on $\gamma^{\prime \prime}$ and $\delta$ phase precipitation of Inconel 718 alloy during deformation\&isothermal treatment. J. Alloys Compd. 2017, 716, 65-72.

9. Sano, K.; Oono, N.; Ukai, S.; Hayashi, S.; Inoue, T.; Yamashita, S.; Yoshitake, T. $\gamma^{\prime \prime}-\mathrm{Ni3Nb}$ precipitate in Fe-Ni base alloy. J. Nucl. Mater. 2013, 442, 389-393. [CrossRef]

10. Lyu, F.; Liu, F.; Hu, X.; Yang, X.; Huang, C.; Shi, D. The delta Phase Precipitation of an Inconel 718 Superalloy Fabricated by Electromagnetic Stirring Assisted Laser Solid Forming. Materials 2019, 12, 2604. [CrossRef]

11. Nunes, R.M.; Pereira, D.; Clarke, T.; Hirsch, T.K. Delta Phase Characterization in Inconel 718 Alloys Through X-ray Diffraction. ISIJ Int. 2015, 55, 2450-2454. [CrossRef]

12. Deng, D.; Moverare, J.; Peng, R.L.; Söderberg, H. Microstructure and anisotropic mechanical properties of EBM manufactured Inconel 718 and effects of post heat treatments. Mater. Sci. Eng. A 2017, 693, 151-163. [CrossRef]

13. Zhang, D.; Feng, Z.; Wang, C.; Wang, W.; Liu, Z.; Niu, W. Comparison of microstructures and mechanical properties of Inconel 718 alloy processed by selective laser melting and casting. Mater. Sci. Eng. A 2018, 724, 357-367. [CrossRef]

14. Huang, W.; Yang, J.; Yang, H.; Jing, G.; Wang, Z.; Zeng, X. Heat treatment of Inconel 718 produced by selective laser melting: Microstructure and mechanical properties. Mater. Sci. Eng. A 2019, 750, 98-107. [CrossRef]

15. Yan, S.; Wang, Q.; Chen, X.; Zhang, C.; Cui, G. Fabrication of highly compact Inconel 718 alloy by spark plasma sintering and solution treatment followed by aging. Vacuum 2019, 163, 194-203. [CrossRef]

16. Elissalde, C.; Chung, U.C.; Josse, M.; Goglio, G.; Suchomel, M.R.; Majimel, J.; Weibel, A.; Soubie, F.; Flaureau, A.; Fregeac, A.; et al. Single-step sintering of zirconia ceramics using hydroxide precursors and Spark Plasma Sintering below $400{ }^{\circ} \mathrm{C}$. Scr. Mater. 2019, 168, 134-138. [CrossRef]

17. Olevsky, E.A.; Froyen, L. Impact of Thermal Diffusion on Densification During SPS. J. Am. Ceram. Soc. 2009, 92, S122-S132. [CrossRef]

18. Chang, L.; Sun, W.; Cui, Y.; Zhang, F.; Yang, R. Effect of heat treatment on microstructure and mechanical properties of the hot-isostatic-pressed Inconel 718 powder compact. J. Alloys Compd. 2014, 590, $227-232$. [CrossRef]

19. Wan, H.-Y.; Zhou, Z.-J.; Li, C.-P.; Chen, G.-F.; Zhang, G.-P. Enhancing Fatigue Strength of Selective Laser Melting-Fabricated Inconel 718 by Tailoring Heat Treatment Route. Adv. Eng. Mater. 2018, 20, 1800307. [CrossRef]

20. Wang, L.Y.; Zhou, Z.J.; Li, C.P.; Chen, G.F.; Zhang, G.P. Comparative investigation of small punch creep resistance of Inconel 718 fabricated by selective laser melting. Mater. Sci. Eng. A 2019, 745, 31-38. [CrossRef] 
21. Niu, H.Z.; Chen, Y.F.; Zhang, D.L.; Zhang, Y.S.; Lu, J.W.; Zhang, W.; Zhang, P.X. Fabrication of a powder metallurgy Ti2AlNb-based alloy by spark plasma sintering and associated microstructure optimization. Mater. Des. 2016, 89, 823-829. [CrossRef]

22. Chua, A.S.; Brochu, M.; Bishop, D.P. Spark plasma sintering of prealloyed aluminium powders. Powder Metall. 2015, 58, 51-60. [CrossRef]

23. Mahathaninwong, N.; Plookphol, T.; Wannasin, J.; Wisutmethangoon, S. T6 heat treatment of rheocasting $7075 \mathrm{Al}$ alloy. Mater. Sci. Eng. A 2012, 532, 91-99. [CrossRef]

24. Mondet, M.; Barraud, E.; Lemonnier, S.; Allain, N.; Grosdidier, T. Optimisation of the mechanical properties of a Spark Plasma Sintered (SPS) magnesium alloy through a post-sintering in-situ precipitation treatment. J. Alloys Compd. 2017, 698, 259-266. [CrossRef]

25. Ma, S.; Yang, Y.; Li, A.; Zhou, S.; Shi, L.; Wang, S.; Liu, M. Effects of temperature on microstructure and mechanical properties of IN718 reinforced by reduced graphene oxide through spark plasma sintering. J. Alloys Compd. 2018, 767, 675-681. [CrossRef]

26. AMS Standard 5663, Nickel Alloy, Corrosion and Heat-Resistant, Bars, Forgings, and Rings; SAE International Aerospace: New York, NY, USA, 2004.

27. ASTM Standard E9-89a(2000), Standard Test Methods of Compression Testing of Metallic Materials at Room Temperature; ASTM International: West Conshohocken, PA, USA, 2000.

28. ASTM Standard E112, Standard Test Methods for Determining Average Grain Size; ASTM International: West Conshohocken, PA, USA, 2012.

29. Anderson, M.; Thielin, A.L.; Bridier, F.; Bocher, P.; Savoie, J. $\delta$ Phase precipitation in Inconel 718 and associated mechanical properties. Mater. Sci. Eng. A 2017, 679, 48-55. [CrossRef]

30. Strondl, A.; Fischer, R.; Frommeyer, G.; Schneider, A. Investigations of MX and $\gamma^{\prime} / \gamma^{\prime \prime}$ precipitates in the nickel-based superalloy 718 produced by electron beam melting. Mater. Sci. Eng. A 2008, 480, 138-147. [CrossRef]

31. Reed, R.C. The Superalloys Fundamentals and Applications; Cambridge University Press: Cambridge, UK, 2006; pp. 55-65.

32. PeakFit ${ }^{\circledR} 4.0$ for Windows ${ }^{\circledR}$ User's Manual; SPSS Inc.: Chicago, IL, USA, 1997.

33. Özgün, Ö.; Gülsoy, H.Ö.; Findik, F.; Yilmaz, R. Microstructure and mechanical properties of injection moulded Nimonic-90 superalloy parts. Powder Metall. 2012, 55, 405-414. [CrossRef]

34. Özgün, Ö.; Özkan Gülsoy, H.; Yilmaz, R.; Findik, F. Injection molding of nickel based 625 superalloy: Sintering, heat treatment, microstructure and mechanical properties. J. Alloys Compd. 2013, 546, 192-207. [CrossRef]

35. Singh, S.S.; Williams, J.J.; Stannard, T.J.; Xiao, X.; Carlo, F.D.; Chawla, N. Measurement of localized corrosion rates at inclusion particles in AA7075 by in situ three dimensional (3D) X-ray synchrotron tomography. Corros. Sci. 2016, 104, 330-335. [CrossRef]

36. Li, X.; Shi, J.J.; Wang, C.H.; Cao, G.H.; Russell, A.M.; Zhou, Z.J.; Li, C.P.; Chen, G.F. Effect of heat treatment on microstructure evolution of Inconel 718 alloy fabricated by selective laser melting. J. Alloys Compd. 2018, 764, 639-649. [CrossRef]

37. Cao, G.H.; Sun, T.Y.; Wang, C.H.; Li, X.; Liu, M.; Zhang, Z.X.; Hu, P.F.; Russell, A.M.; Schneider, R.; Gerthsen, D.; et al. Investigations of $\gamma^{\prime}, \gamma^{\prime \prime}$ and $\delta$ precipitates in heat-treated Inconel 718 alloy fabricated by selective laser melting. Mater. Charact. 2018, 136, 398-406. [CrossRef]

38. Özgün, Ö.; Gülsoy, H.Ö.; Yılmaz, R.; Fındık, F. Microstructural and mechanical characterization of injection molded 718 superalloy powders. J. Alloys Compd. 2013, 576, 140-153. [CrossRef]

39. You, X.; Tan, Y.; Zhao, L.; You, Q.; Wang, Y.; Ye, F.; Li, J. Effect of solution heat treatment on microstructure and electrochemical behavior of electron beam smelted Inconel 718 superalloy. J. Alloys Compd. 2018, 741, 792-803. [CrossRef]

40. You, X.; Tan, Y.; Shi, S.; Yang, J.-M.; Wang, Y.; Li, J.; You, Q. Effect of solution heat treatment on the precipitation behavior and strengthening mechanisms of electron beam smelted Inconel 718 superalloy. Mater. Sci. Eng. A 2017, 689, 257-268. [CrossRef]

41. Oradei-Basile, A.; Radavich, J.F. Superalloys 718, 625, 706 and Derivatives; The Minerals, Metals \&Materials Society: Warrendale, PA, USA, 2005; p. 325. 
42. Chang, L.; Sun, W.; Cui, Y.; Yang, R. Influences of hot-isostatic-pressing temperature on microstructure, tensile properties and tensile fracture mode of Inconel 718 powder compact. Mater. Sci. Eng. A 2014, 599, 186-195. [CrossRef]

43. Goel, S.; Sittiho, A.; Charit, I.; Klement, U.; Joshi, S. Effect of post-treatments under hot isostatic pressure on microstructural characteristics of EBM-built Alloy 718. Addit. Manuf. 2019, 28, 727-737. [CrossRef]

44. Azadian, S.; Wei, L.-Y.; Warren, R. Delta phase precipitation in Inconel 718. Mater. Charact. 2004, 53, 7-16. [CrossRef]

45. Raghavan, S.; Zhang, B.; Wang, P.; Sun, C.-N.; Nai, M.L.S.; Li, T.; Wei, J. Effect of different heat treatments on the microstructure and mechanical properties in selective laser melted INCONEL 718 alloy. Mater. Manuf. Processes 2017, 32, 1588-1595. [CrossRef]

46. Liu, L.; Tanaka, K.; Hirose, A.; Kobayashi, K.F. Effects of precipitation phases on the hydrogen embrittlement sensitivity of Inconel 718. Sci. Technol. Adv. Mater. 2002, 3, 335-344. [CrossRef]

47. Kuo, Y.-L.; Horikawa, S.; Kakehi, K. The effect of interdendritic $\delta$ phase on the mechanical properties of Alloy 718 built up by additive manufacturing. Mater. Des. 2017, 116, 411-418. [CrossRef]

48. Strößner, J.; Terock, M.; Glatzel, U. Mechanical and Microstructural Investigation of Nickel-Based Superalloy IN718 Manufactured by Selective Laser Melting (SLM). Adv. Eng. Mater. 2015, 17, 1099-1105. [CrossRef]

49. Chlebus, E.; Gruber, K.; Kuźnicka, B.; Kurzac, J.; Kurzynowski, T. Effect of heat treatment on the microstructure and mechanical properties of Inconel 718 processed by selective laser melting. Mater. Sci. Eng. A 2015, 639, 647-655. [CrossRef]

(C) 2019 by the authors. Licensee MDPI, Basel, Switzerland. This article is an open access article distributed under the terms and conditions of the Creative Commons Attribution (CC BY) license (http://creativecommons.org/licenses/by/4.0/). 